\title{
Guy Gueudet, L'art de la lettre humaniste
}

\section{Dario Cecchetti}

\section{(2) OpenEdition}

\section{Journals}

\section{Edizione digitale}

URL: http://journals.openedition.org/studifrancesi/34471

DOI: 10.4000/studifrancesi.34471

ISSN: 2421-5856

\section{Editore}

Rosenberg \& Sellier

\section{Edizione cartacea}

Data di pubblicazione: 1 novembre 2005

Paginazione: 398

ISSN: 0039-2944

\section{Notizia bibliografica digitale}

Dario Cecchetti, «Guy Gueudet, L'art de la lettre humaniste», Studi Francesi [Online], 146 (XLIX | II) | 2005,

online dal 30 novembre 2015, consultato il 18 avril 2021. URL: http://journals.openedition.org/

studifrancesi/34471; DOI: https://doi.org/10.4000/studifrancesi.34471

\section{Questo documento è stato generato automaticamente il 18 avril 2021.}

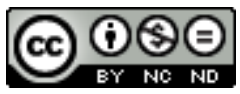

Studi Francesi è distribuita con Licenza Creative Commons Attribuzione - Non commerciale - Non opere derivate 4.0 Internazionale. 


\title{
Guy Gueudet, L'art de la lettre humaniste
}

\author{
Dario Cecchetti
}

\section{NOTIZIA}

GUY GUEUDET, L'art de la lettre humaniste, textes réunis par FRANCINE WILD, Paris, Champion («Bibliothèque littéraire de la Renaissance», LX), 2004, pp. 723.

1 Un gruppo di colleghi e amici di Guy Gueudet pubblica postumo il materiale lasciato dal compianto studioso di Guillaume Budé che stava, al momento della scomparsa, completando un'ambiziosa ricerca sull'arte epistolare rinascimentale. Per quanto incompiuto, il lavoro è imponente e sicuramente utile e denso di spunti per ulteriori indagini. Soprattutto fornisce una ricca documentazione, poco conosciuta e spesso inedita, sull'epistolografia e sulla sua evoluzione, e, ricostruendo la storia del protocollo epistolare, ne mette in evidenza le implicazioni sociologiche e ideologiche delle variazioni. Il testo a noi giunto si divide in due parti. La prima (Guillaume Budé epistolier, pp. 15- 214) indica in Budé il punto di partenza di una riflessione sul dictamen epistolare in generale all'epoca rinascimentale. Ma soprattutto cerca di ritracciarne la tradizione precedente, medievale e preumanistica. La seconda parte (Rhétorique épistolaire. Études des manuels, pp. 217-576), forse la più interessante e più utile, compie uno spoglio metodico dei manuali medievali e umanistici - dalle artes dictaminis medievali fino ad Erasmo e ai suoi epigoni - di cui studia anche le implicazioni sociologiche. Si tratta, insomma, di una pubblicazione che può suggerire delle piste di ricerca agli specialisti di grammatica, retorica, stilistica, storia della cultura e sociologia della letteratura. 